\title{
DIDMOAD syndrome with megacystis and megaureter
}

\author{
P. Chu ${ }^{1}$, W.G. Staff ${ }^{2}$, J.A. Morris ${ }^{3}$ and J.M. Polak ${ }^{4}$
}

${ }^{1}$ Department of Medicine, Royal Lancaster Infirmary, Lancaster, ${ }^{2}$ Department of Urology, Royal Lancaster Infirmary, Lancaster, ${ }^{3}$ Department of Pathology, Lancaster Moor Hospital, Lancaster LA1 3JR, and ${ }^{4}$ Department of Histochemistry, Royal Postgraduate Medical School, Hammersmith Hospital, Du Cane Road, London W12 OHS, UK.

\begin{abstract}
Summary: A case of DIDMOAD syndrome (diabetes insipidus, diabetes mellitus, optic atrophy and nerve deafness) is described. There was unusually severe urinary tract dilatation which led to an ileal conduit diversion. Immunohistological study of the bladder wall and ureter revealed a marked diminution in nerve fibres, which may have been primary or secondary to the muscle hypertrophy. The possible pathogenesis of the urinary tract dilatation is discussed in relation to this finding.
\end{abstract}

Introduction

The DIDMOAD syndrome is a rare familial disease characterized by diabetes insipidus, diabetes mellitus, optic atrophy and nerve deafness. The association of diabetes mellitus and optic atrophy was first described as a familial event by Wolfram (1938) and the syndrome has been reviewed by Rose et al. (1966), Page et al. (1976) and Cremers et al. (1977). It is thought to be due to a single recessive gene although the pathogenesis is unknown. A common component of the syndrome is urinary tract dilatation which varies from mild hydronephrosis to megaureter and megacystis (Raiti et al., 1963; Bretz et al., 1970; Moore, 1971; Marquardt \& Loriaux, 1974; Page et al., 1976; Aragona et al., 1983). The most frequently proferred explanation for the urinary tract dilatation is that high urine flow due to diabetes insipidus causes passive dilatation. However, we report a case of DIDMOAD syndrome with megacystis and megaureter in which immunohistological studies of the bladder wall and ureter demonstrated a marked diminution in nerve fibres. This might be of pathogenic significance.

\section{Case report}

The patient developed insulin-dependent diabetes mellitus at 8 years of age. There was no history of this condition in his immediate family which included three male siblings. At age 12 years he complained of blurred vision and was found to have impaired visual

Correspondence: J.A. Morris, M.A., M.B., B.Chir., M.R.C.Path.

Accepted: 20 February 1986 acuity (6/12 both eyes, uncorrectable) and bilateral optic atrophy. There was no evidence of diabetic retinopathy. He remained relatively well in his teens with normal schooling and growth, apart from hypoglycaemic attacks. He first presented to the Urological Department at 23 years of age. His main complaint was lack of urinary control which had occurred regularly each night during sleep for the previous 9 months, and which also occurred if he dozed during the day. He was also aware of extreme thirst and had observed that he was producing a large amount of urine daily, in spite of the fact that his diabetes mellitus was under satisfactory control. He was apparently experiencing normal bladder sensation and said that he was achieving normal erections although ejaculation was infrequent. Physical examination revealed that his bladder was distended beyond the umbilicus. Apart from optic atrophy (visual acuity $6 / 24$ on the right and $6 / 36$ on the left with glasses) there was no other detectable abnormality of the central nervous system. There was no evidence of peripheral neuropathy or of orthostatic hypotension.

Initial urological investigations included an intravenous urogram (Figure 1). This showed gross upper tract dilatation in association with the large bladder. At that time his blood urea was $7.2 \mathrm{mmol} /$ litre and serum creatinine $130 \mu \mathrm{mol} / \mathrm{litre}$. His urine was sterile and remained so throughout subsequent investigations and treatment. No reflux was demonstrated on a micturating cystogram. A uretherogram showed normal anatomical features of the posterior urethra (Figure 2). A cystometrogram performed without a preliminary drainage of the bladder showed a rapid rise in pressure leading to detrusor contractions associated with an apparently normal desire to void. 


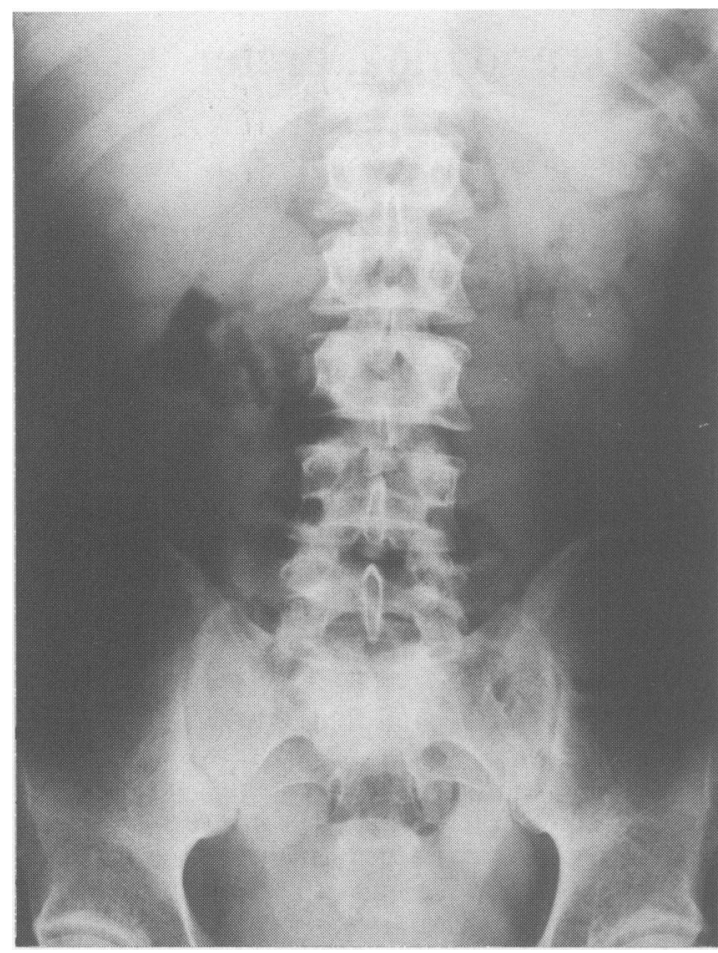

Figure 1 Intravenous urogram 60 minutes (post-micturition) showing gross upper tract dilatation and a large residual urine.

Flow rates were normal. During a period of water deprivation he produced approximately $300 \mathrm{ml}$ urine per hour with a concentration between 176 and $193 \mathrm{mosmol} / \mathrm{kg}$. In this period his serum concentration rose from 289 to $306 \mathrm{mosmol} / \mathrm{kg}$. After an intramuscular injection of $2 \mu \mathrm{g}$ of desmopressin his urine flow rate fell to $220 \mathrm{ml} /$ hour and the maximum concentration achieved was $280 \mathrm{mosmol} / \mathrm{kg}$. These results were consistent with nephrogenic diabetes insipidus, although there was a possible slight response to vasopressin and a concomitant neurogenic diabetes insipidus could not be excluded. There was no subjective hearing deficit but audiometry revealed high tone nerve deafness.

Treatment with desmopressin and chlorpropamide jointly and separately were tried but there was no evidence of any diminished urinary output and in spite of regular bladder emptying his main problem of urinary incontinence persisted. A bladder neck incision was performed followed by a period of catheter drainage. His urine output continued at a high level but his blood urea and creatinine fell from the immediate pre-operative level of $10.6 \mathrm{mmol} /$ litre and $153 \mu \mathrm{mol} /$ litre, respectively, to $7.1 \mathrm{mmol} /$ litre and $121 \mu \mathrm{mol} /$ litre post-operatively whilst on catheter

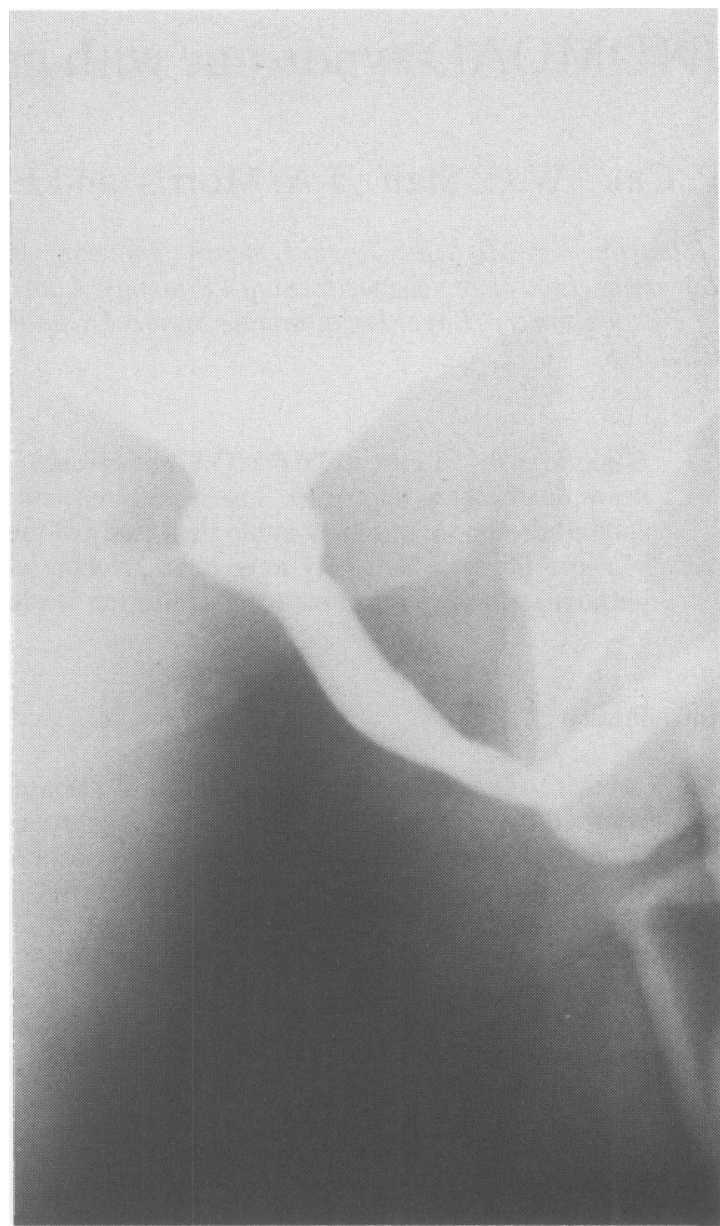

Figure 2 Voiding urethrogram. Showing normal bladder neck and posterior urethra.

drainage. Isotope renography performed postoperatively, whilst still on catheter drainage, showed a significant improvement from the pre-operative state. However, after removal of his catheter his blood urea and creatinine rose to $8.9 \mathrm{mmol} /$ litre and $158 \mu \mathrm{mol} /$ litre respectively and his condition returned to its former state.

A urinary diversion was considered. A major obstacle to this was the vast amount of urine being produced which might swamp the appliance. Although whilst on catheter drainage the patient's general condition and renal function as judged by blood urea, creatinine and renography had improved there had been little fall in urine output. However it was thought that improved drainage might improve the nephrogenic component of his diabetes insipidus. Thus, 10 months after presentation the patient was submitted to ileal conduit diversion. Permission for a full thickness biopsy of the 
bladder was obtained and this together with specimens of both ureters, appendix and off-cuts of ileum were sent for histological examination.

The patient made an uneventful recovery. At the time of discharge his urine output had fallen to between 3700 and $4500 \mathrm{ml} / \mathrm{day}$, and his blood urea to $5.1 \mathrm{mmol} /$ litre and creatinine to $122 \mu \mathrm{mol} /$ litre. A post-operative intravenous urogram showed satisfactory resolution of the upper tract distension (Figure 3). A subsequent water deprivation test revealed a continuing inability to concentrate the urine beyond $200 \mathrm{mosmol} / \mathrm{kg}$, but following intramuscular vasopressin the urine reached a maximum concentration of $320 \mathrm{mosmol} / \mathrm{kg}$. These results are difficult to interpret but the simplest explanation is that there was both nephrogenic and neurogenic diabetes insipidus and that the former component had improved following the drainage procedure.

Three years post-operatively he was working full time. He had normal renal function and his daily urine output averaged $5900 \mathrm{ml}$. He had decided to take no medical treatment other than that for his diabetes mellitus as he felt it unnecessary.

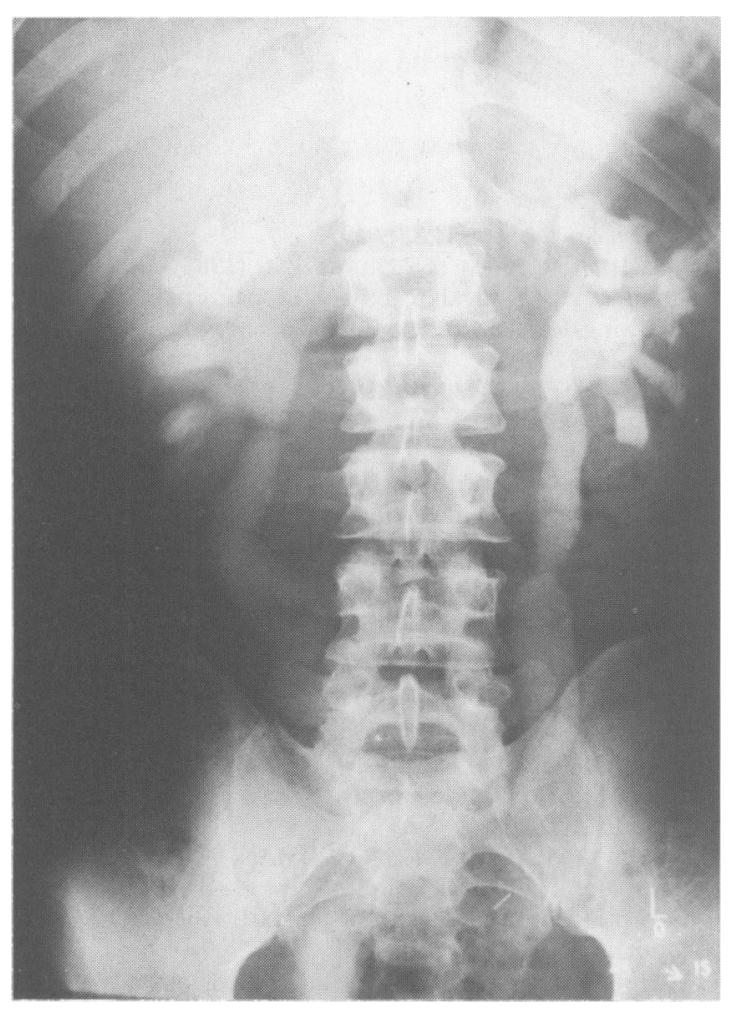

Figure 3 Intravenous urogram following ileal conduit diversion. Upper tract dilatation persists but is considerably improved compared with the pre-operative state.

\section{Histopathology}

Sections of the bladder and ureters showed marked thickening of the wall due to muscular hypertrophy and fibrosis. There was submucosal oedema with mild inflammation and moderate hyperplasia of the transitional epithelial lining. The appendix and small intestine were morphologically normal.

Immunohistological staining was performed on cryostat sections of snap-frozen formalin-fixed material. A conventional immunoperoxidase bridge technique (Sternberger, 1979) was used with optimal dilutions of primary antisera and a full range of positive, negative and blocking controls as detailed elsewhere (Gu et al., 1985). Primary antisera reactive against the following were used; dopamine- $\beta$-hydroxylase (DBH, a marker for catecholaminergic nerves), neurone-specific enolase (NSE, a general neural marker), S-100 (a protein present in glial cells), the amine serotonin (5-HT) and the peptides somatostatin, neuropeptide Y (NPY), vasoactive intestinal peptide (VIP) and peptide histidine isoleucidine (PHI). There was gross depletion of nerves in bladder and ureters with immunostaining varying from nil to minimal. By contrast, in the appendix and small intestine, apart from a reduction in VIP, the staining appeared normal.

\section{Discussion}

This patient had diabetes mellitus, diabetes insipidus, optic atrophy and high tone nerve deafness and thus fulfills the criteria for the DIDMOAD syndrome. However, there was no family history. The precise cause of diabetes insipidus in this condition is somewhat uncertain although it is thought to arise because of impaired antidiuretic hormone secretion aggravated by a nephrogenic component which is secondary to urinary tract dilatation (Cremers et al., 1977). The results in this case fit with this explanation, although whilst the nephrogenic component of the diabetes insipidus was proven, the neurogenic component was not.

There is no evidence that the urinary tract dilatation in the DIDMOAD syndrome is due to organic obstruction (Page et al., 1976). However there is evidence of functional obstruction as intervention to improve drainage by self catheterization (Aragona $e t$ al., 1983), bladder neck resection (Cremers et al., 1977) or formation of an ideal conduit (Moore, 1971) leads to an improvement in hydronephrosis. In this case improved drainage by bladder neck resection and then by an ileal conduit led to a fall in blood urea and creatinine and a reduction in urine volume consistent with reduced outflow pressure and improved renal tubular function. Page et al. (1976) have suggested that 
the high urine flow rate caused by diabetes insipidus leads to progressive passive dilatation of the urinary tract and that this together with inattention to periodic bladder emptying impairs detrusor action producing a functional obstruction. This explanation is consistent with the observation that megaureter and megacystis do occur in both hereditary nephrogenic diabetes insipidus (Carter \& Goodman, 1963; ten Bensel \& Peters, 1970) and hereditary anti-diuretic hormone sensitive diabetes insipidus (Pender \& Fraser, 1953; Wheeler \& Adelson, 1964; Boyd et al., 1980). Urinary tract dilatation does not develop in adult onset diabetes insipidus (Fink, 1928; Page et al., 1976) but this might be because the high flow rate operates over a shorter period or because the childhood tract is more susceptible to dilatation.

An alternative explanation for urinary tract dilatation is that there is a selective neuropathy affecting the bladder and ureters. This could be either a primary degenerative condition or secondary to diabetes mellitus. The latter is somewhat unlikely as in this case and in many (Page et al., 1976) but not all (Cremers et al., 1977; Verri et al., 1982) previous cases there was no evidence of diabetic autonomic neuropathy or peripheral neuropathy. Immunohistological studies of neuropathic bladders (Gu et al., 1983, 1984) have revealed a characteristic picture of proliferating S-100

\section{References}

ARAGONA, F., GARAT, J.M. \& MARTINEZ, E. (1983). Urological aspects of Wolfram's syndrome. European Urology, 9, 75.

BOYD, S.D., RAZ, S. \& EHRLICH, R.M. (1980). Diabetes insipidus and nonobstructive dilation of urinary tract. Urology, 16, 266.

BRETZ, G.W., BAGHDASSARIAN, A., GRABER, J.D., ZACHERLE, B.J., NORUM, R.A. \& BLIZZARD, R.M. (1970). Coexistence of diabetes mellitus and insipidus and optic atrophy in two male siblings. American Journal of Medicine, 48, 398.

CARTER, R.D. \& GOODMAN, A.D. (1963). Nephrogenic diabetes insipidus accompanied by massive dilatation of the kidneys, ureters and bladder. Journal of Urology, 89, 366.

CREMERS, C.W.R.J., WIJDEVELD, P.G.A.B. \& PINCKERS, A.J.L.G. (1977). Juvenile diabetes mellitus, optic atrophy, hearing loss, diabetes insipidus, atonia of the urinary tract and bladder, and other abnormalities (Wolfram Syndrome). Acta Paediatrica Scandinavica, 264, 3.

FINK, E.B. (1928). Diabetes insipidus. Archives of Pathology, 6, 102.

GU, J., ISLAM, K.N., HEHIR, M. \& POLAK, J.M. (1983). The increase of $\mathrm{S} 100$ in the neuropathic bladder. Journal of Pathology, 139, 502.

GU, J., POLAK, J.M., DEANE, A., COCCHIA, D. \& MICHETTI, F. (1984). Increase of S-100 immunoreactivity in the urinary bladder from patients with multiple sclerosis, an indication of peripheral neuronal lesion. American Journal staining Schwann cells which was not seen in this case. The Schwann cell proliferation is thought to occur when nerve fibre degeneration and regeneration occur concomitantly. However, a purely degenerative neuropathy could, in theory, lead to a loss of nerve fibres without Schwann cell hyperplasia. In fact focal progressive neuropathy is in many ways the hallmark of the DIDMOAD syndrome leading to progressive optic atrophy, progressive high tone deafness and impaired anti-diuretic hormone secretion from the hypothalamus. The marked diminution in nerve fibre staining observed in the bladder and ureter in this case supports this concept although the possibility that the decreased density of nerve fibres is secondary to muscular hypertrophy cannot be excluded with confidence. If there is a primary degenerative neuropathy it is clear that it is focal as immunohistological staining revealed a normal density of nerve fibres in the appendix and small intestine.

Further immunohistological studies of the urinary tract in the DIDMOAD syndrome, using a wide range of antisera against neurone-specific antigens are required to see if the changes that we have noted are a constant finding and to determine whether they are the cause of the urinary tract dilatation or a consequence of it.

of Clinical Pathology, 82, 649.

GU, J., HUANG, W.M. \& POLAK, J.M. (1985). Stability of immunocytochemical reactivity of neuronal substances following delayed fixation. Journal of Neurosciences Methods, 12, 297.

MARQUARDT, J.L. \& LORIAUX, D.L. (1974). Diabetes mellitus and optic atrophy. Archives of Internal Medicine, 134, 32.

MOORE, J.R. (1971). Juvenile diabetes mellitus, diabetes insipidus and neurological abnormalities. Proceedings of the Royal Society of Medicine, 64, 730.

PAGE, M. MC B., ASMAL, A.C. \& EDWARDS, C.R.W. (1976). Recessive inheritance of diabetes: the syndrome of diabetes insipidus, diabetes mellitus, optic atrophy and deafness. Quarterly Journal of Medicine, 179, 505.

PENDER, C.B., \& FRASER, F.C. (1953). Dominant inheritance of diabetes mellitus. Pediatrics, 11, 246.

RAITI, S., PLOTKIN, S. \& NEWNS, G.H. (1963). Diabetes mellitus and insipidus in two sisters. British Medical Journal, 2, 1625.

ROSE, R.C., FRASER, G.R., FRIEDMAN, A.I. \& KOHNER, E.M. (1966). The association of juvenile diabetes mellitus and optic atrophy; clinical and genetical aspects. Quarterly Journal of Medicine, 139, 385.

STERNBERGER, L.A. (1979). The unlabelled antibody peroxide anti-peroxidase (PAP) method. In Immunocytochemistry, Sternberger, L.A. (ed). p. 104-169. John Wiley: New York.

TEN BENSEL, R.W. \& PETERS, E.R. (1970). Progressive 
hydronephrosis, hydroureter and dilatation of the bladder in siblings with congenital nephrogenic diabetes insipidus. Journal of Pediatrics, 77, 439.

VERRI, A., BORUTTI, G., SANDRINI, G., POLONI, M. \& VAILATI, A. (1982). A case of Wolfram syndrome: neurological features. Italian Journal of Neurological Sciences, 4, 351.
WHEELER, J.S. \& ADELSON, W.J. (1964). Pituitary diabetes insipidus associated with progressive urinary tract dilatation. Journal of Urology, 92, 64.

WOLFRAM, D.J. (1938). Diabetes mellitus and simple optic atrophy among siblings: Report of four cases. Proceedings of the Staff Meetings of the Mayo Clinic, 13, 715. 